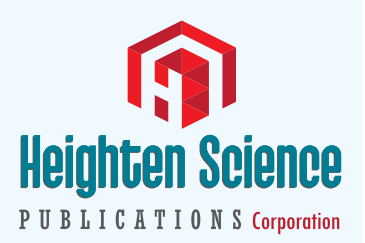

ISSN

2639-9938
*Address for Correspondence: Leandro Bueno Bergantin, Laboratory of Autonomic and Cardiovascular Pharmacology, Department of Pharmacology, Federal University of São PauloPaulista School of Medicine, R. Sena Madureira, 1500 - Vila Clementino, São Paulo - SP, 04021001, Brazil, Email: leanbio39@yahoo.com.br

Submitted: 15 December 2016

Approved: 28 January 2017

Published: 30 January 2017

Copyright: @2017 Caricati-Neto A, et al. This is an open access article distributed under the Creative Commons Attribution License, which permits unrestricted use, distribution, and reproduction in any medium, provided the original work is properly cited

Keywords: $\mathrm{Ca}^{2+} / \mathrm{cAMP}$ signaling interaction; serotoninergic neurotransmission;

Monoaminergic neurotransmission; Depression

D) Check for updates

\title{
Novel Challenges for the
} Therapeutics of Depression: Pharmacological Modulation of Interaction between the Intracellular Signaling Pathways Mediated by $\mathrm{Ca}^{2+}$ and CAMP

\author{
Afonso Caricati-Neto and Leandro Bueno Bergantin* \\ Laboratory of Autonomic and Cardiovascular Pharmacology, Department of Pharmacology, \\ Federal University of São Paulo- Paulista School of Medicine, R. Sena Madureira, 1500 - Vila \\ Clementino, São Paulo - SP, 04021-001, Brazil
}

\section{ABSTRACT}

Depression is a psychiatric disease resulting mainly by dysfunction of serotoninergic and monoaminergic neurotransmission in central nervous system (CNS). Due to the multifaceted nature of depression and our limited understanding on its etiology, depression is difficult to be treated with currently available pharmaceuticals. Then, new therapeutic strategies for depression have been proposed. Since 1975, several clinical studies have reported that L-type $\mathrm{Ca}^{2+}$ channel blockers (CCBs), used in anti-hypertensive therapy, produce increase of plasma catecholamine levels and tachycardia, typical symptoms of sympathetic hyperactivity. Despite these adverse effects of CCBs have been initially attributed to adjust reflex of arterial pressure, during almost four decades these enigmatic phenomena remained unclear. In 2013, we discovered that this paradoxical sympathetic hyperactivity produced by CCBs results from the increase of catecholamines release from sympathetic nerves, and adrenal chromaffin cells, due to its modulatory action on the interaction between intracellular signaling pathways mediated by $\mathrm{Ca}^{2+}$ and $\mathrm{CAMP}\left(\mathrm{Ca}^{2+} / \mathrm{CAMP}\right.$ signalling interaction). Then, the pharmacological modulation of this interaction by combined use of L-type CCBs, and CAMP-enhancer compounds, could be a more efficient (and safer) therapeutic strategy to produce increase of serotoninergic and monoaminergic neurotransmission in the CNS due to enhance of serotonin and monoamines release, thus attenuating clinical symptoms of depression in humans.

\section{INTRODUCTION}

Depression is a psychiatric disease resulting mainly by dysfunction of serotoninergic and monoaminergic neurotransmission in central nervous system (CNS) [1,2]. Depression is a severe global illness, becoming more and more common each decade. Because of specific symptoms, it is considered as a leading cause of disability all over the world with a high death factor due to suicides. There are many antidepressants used in the therapy, but still more than one-third of patients do not respond to the current therapy [2]. The heterogeneous nature of the illness and its complex, and unclear etiology, may be responsible for treatment difficulties. Next to the main monoaminergic hypothesis of depression, there are also many other approaches connected with the pathophysiology of this disease, including hypothalamic-pituitaryadrenal axis dysregulation, dopaminergic, cholinergic, glutamatergic or GABA-ergic neurotransmission [2]. Nevertheless, it can be unambiguously stated that serotonergic, 
noradrenergic and dopaminergic systems (monoaminergic neurotransmission) are precisely associated with pathogenesis of depression, and should be therefore considered as valuable targets in patients' treatment. In this review, we discuss novel strategies to treat depression, throughout our recent discovery entitled "calcium paradox" phenomenon due to interaction between the intracellular signalling pathways mediated by $\mathrm{Ca}^{2+}$ and cAMP ( $\mathrm{Ca}^{2+} / \mathrm{cAMP}$ signaling interaction) [1,3-8].

\section{CURRENT THERAPY TO TREAT DEPRESSION}

Depression is an incapacitating psychiatric condition that causes a significant problem on individuals and society. There is still a lack of a clear understanding of the neuropathological changes associated with this illness, and the efficacy of antidepressants is still far from the best [9]. Research into antidepressant therapies has derived from observations in human trials and animal models after the first monoaminergic hypothesis emerged (about six decades ago). However, glutamatergic modulators, such as ketamine also have become the forefront of antidepressant exploration, especially for treatment-resistant depression and suicidal ideation [9]. The glutamatergic hypothesis of depression is not novel, however other NMDA receptor modulators do not seem to share the rapid and sustained effects of ketamine, suggesting that a unique combination of intracellular targets might be involved in its effect [9]. Interestingly, inflammation can impact the glutamatergic system enhancing excitotoxicity and decreasing neuroplasticity. The points of convergence between the inflammatory and glutamatergic hypotheses of depression are not completely established, especially regarding the effects of fast-acting antidepressants $[9,10]$.

Nonetheless, the monoamine hypothesis of depression continues to dominate the field and clinical trials, which postulates that an imbalance in monoaminergic neurotransmission is causally related to the clinical features of depression [10]. Anti-depressants influence serotonin whose main goal consist to raise serotonin concentrations, thereby increasing serotonergic transmission at the level of the synapse, for example by inhibiting the serotonin transporter. However, the serotonin system is multifaceted. Different serotonin receptor subtypes turn the serotonergic system into a complex neurochemical arrangement that influences diverse neurotransmitters in various brain regions. Classical antidepressants, as well as other psychopharmacological agents have various crucial effects on serotonin receptors. Researchers aim to provide a useful characterization of serotonin receptor subtypes in the treatment of depression. Clarifying the mode of action, and the interplay of serotonin receptors with pharmacological agents should help elucidate antidepressant mechanisms and typical side effects to better understanding. In addition, clinical medicine featured the novel antidepressants vortioxetine, vilazodone and milnacipran/ levomilnacipran with regard to their serotonin receptor targets such as the 5-HT1A, 5-HT3 and 5-HT7, which may account for their specific effects on certain symptoms of depression as well as a characteristic side-effect profile [10].

The combination of novel ideas added to improvements on the discoveries may lead to advances in antidepressant research with the promise of finding compounds that are both effective, and fast-acting, including in patients who have tried other therapies with limited success. In conclusion, new insights for more efficient pharmacological treatments of depression are clearly needed.

\section{NOVEL CHALLENGES FOR THE THERAPEUTICS OF DEPRESSION: PHARMACOLOGICAL MODULATION OF THE CA $^{2+} /$ CAMP SIGNALING INTERACTION}

\section{$\mathrm{CA}^{2+} /$ CAMP SIGNALING INTERACTION: A BRIEF REVIEW}

Several experiments initiated decades ago, using catecholaminergic cells, have originated the concept of stimulus-secretion coupling to elucidate neurotransmitter release and hormone secretion. This concept has been initially resulted from the study 
of cat adrenal gland perfused with acetylcholine executed by Douglas and Rubin in the 1960s [11]. The discovery that increase in the cytosolic $\mathrm{Ca}^{2+}$ concentration $\left(\left[\mathrm{Ca}^{2+}\right] \mathrm{c}\right)$ was a basic requirement for exocytosis in adrenal catecholaminergic cells was made by Baker and Knight in 1970's [12]. In addition, some studies showed that cAMP raises transmitter release at many synapses in autonomic nervous system of vertebrate, including sympathetic and parasympathetic ganglion neurons [13]. Although the cellular and molecular mechanisms involved in these synergistic actions of cAMP on the exocytosis of neurotransmitter and hormones remain uncertain, the evidences suggest that this intracellular messenger can participate in fine regulation of exocytosis due to its modulatory action on the intracellular $\mathrm{Ca}^{2+}$ signals.

In fact, the hypothesis for the $\mathrm{Ca}^{2+} / \mathrm{cAMP}$ signaling interaction has been extensively studied in many cells and tissues. Generally, this interaction results in synergistic effects on cell functions [1,3-8,14,15] and occurs at the level of adenylyl cyclases (AC) or phosphodiesterases (PDE) (Figure 1). The $\mathrm{Ca}^{2+} / \mathrm{cAMP}$ signaling interaction has particularly been extensively studied at the $\mathrm{Ca}^{2+}$ channels [e.g.: ryanodine receptors (RyR)] of the endoplasmic reticulum (ER) $[1,3-8,14,15]$. Phosphorylation of RyR by protein kinase $A(P K A)$, and also inositol trisphosphate receptor $\left(\mathrm{IP}_{3} \mathrm{R}\right)$ at submaximal

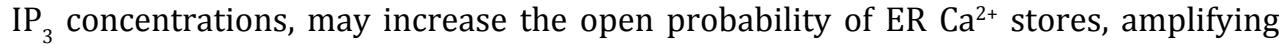

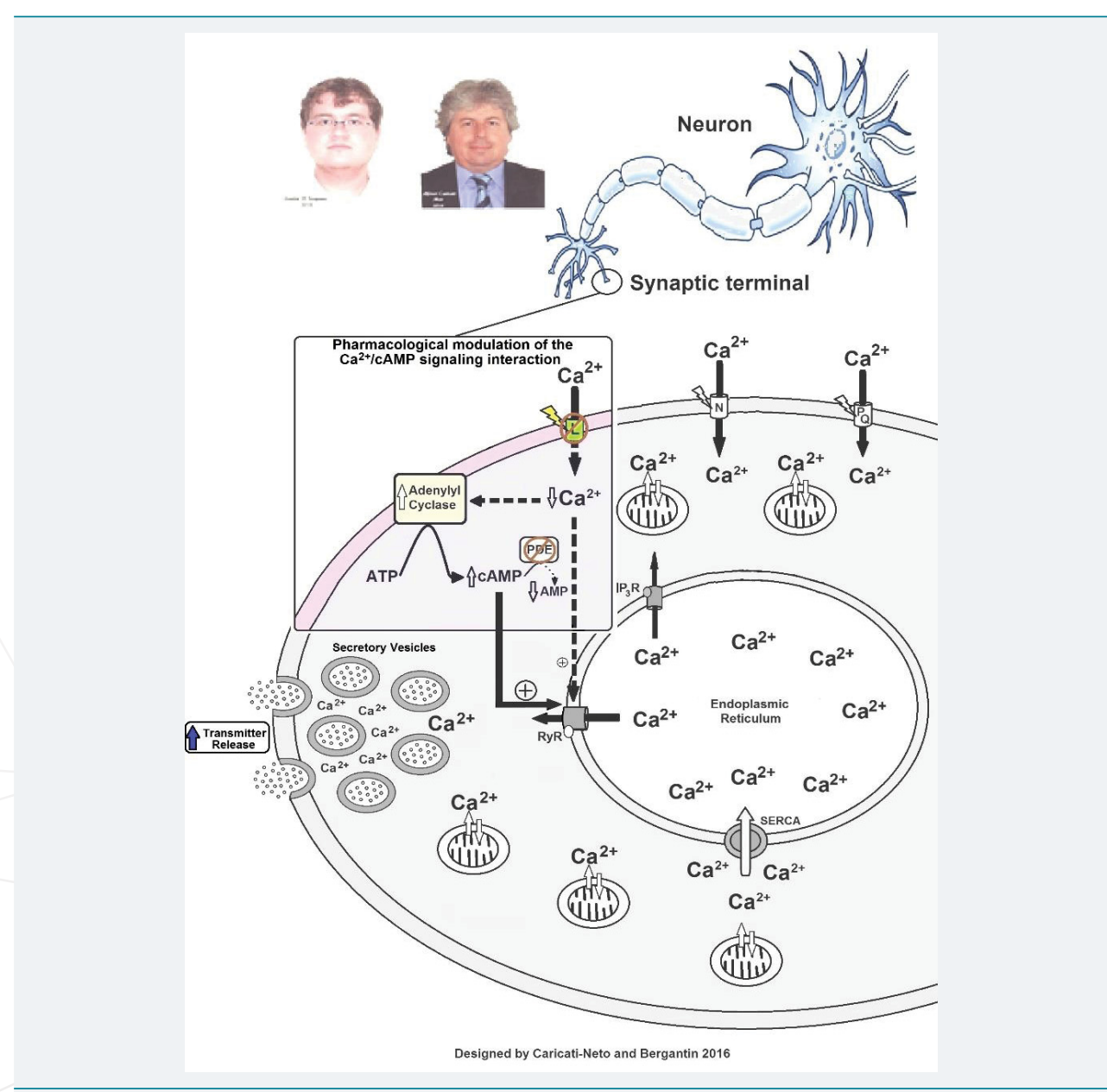

Figure 1: Role of $\mathrm{Ca}^{2+} / \mathrm{cAMP}$ signaling interaction in the neurotransmission. In studies published in 2013, 2015 and 2016 (Caricati-Neto et al. 2015; Bergantin et al. 20132015 and 2016 a,b,c,d), we discovered that the paradoxical hyperactivity of sympathetic neurons produced by L-type CCBs results of its interference on the $\mathrm{Ca}^{2+} / \mathrm{CAMP}^{2}$ signaling interaction involved in the neurotransmitter release. The pharmacological manipulation of the $\mathrm{Ca}^{2+} /$ cAMP interaction by combined use L-type CCBs and cAMP-enhancer compounds could be a new therapeutic strategy for increasing central serotoninergic and monoaminergic neurotransmission in depression. cAMP: cyclic adenosine monophosphate; ATP: adenosine trisphosphate; L-, N-, P/Q-type $\mathrm{Ca}^{2+}$ channels, IP ${ }_{3} \mathrm{R}$ : Inositol trisphosphate receptor; PDE: phosphodiesterase; RyR: ryanodine receptors; SERCA: sarco-endoplasmic $\mathrm{Ca}^{2+}$ ATPase. In addition, store-operated calcium entry (SOCE) is a ubiquitous $\mathrm{Ca}^{2+}$ entry pathway that is activated in response to depletion of Endoplasmic Reticulum- $\mathrm{Ca}^{2+}$ stores, and critically controls the regulation of physiological functions in cell types. 
$\mathrm{Ca}^{2+}$-induced $\mathrm{Ca}^{2+}$ release (CICR) mechanism and cellular responses (Figure 1). Indeed, the concept of the complex cAMP-IP $\mathrm{R}$ interaction, which may mediate the synergistic action of $\mathrm{Ca}^{2+}$ and cAMP signalling, is now emerging [16]. Recent data suggest that IRBIT (IP3 receptors binding protein release with IP3) may become central-stage in the mechanism mediating the synergism between cAMP and $\mathrm{Ca}^{2+}$ signalling pathways by functioning as a "third messenger", which favours the crosstalk between $\mathrm{IP}_{3} \mathrm{Rs}$ and other proteins. Another central component is the classical PKA phosphorylation of $I_{3}$ Rs. For this, IP ${ }_{3} R s$, IRBIT, PKA and the effector proteins have to be assembled into microdomains to allow the efficiency of IRBIT. In resting cells, when cellular IP levels are low, IRBIT is bound to IP ${ }_{3} \mathrm{Rs}$; thus $\mathrm{IP}_{3} \mathrm{Rs}$ work to buffer the availability of free IRBIT [16]. Increases in cAMP levels may lead to dissociation of IRBIT from $\mathrm{IP}_{3}$ receptors, and its translocation to effector proteins, located either at intracellular organelles and/ or the plasma membrane; in this manner, IRBIT functions as a "third messenger" that transmits the information carried out by the second messenger's cAMP and IP ${ }_{3}$. At the same time, IRBIT integrates, and synergizes, the activity of the cAMP and $\mathrm{Ca}^{2+}$ signalling systems, providing a molecular mechanism for the synergistic action between them.

Recent evidences suggest that $\mathrm{Ca}^{2+} / \mathrm{cAMP}$ signaling interaction participates in exocytosis regulation of neurons and neuroendocrine cells [1,3-8]. Then, dysfunctions of cellular homeostasis of $\mathrm{Ca}^{2+}$ and/or cAMP in these cells could result in the dysregulation of $\mathrm{Ca}^{2+} / \mathrm{cAMP}$ signaling interaction and exocytotic response, or could be a novel therapeutic target for medicines (Figure 1).

\section{PARADOXICAL EFFECTS OF CCBS AND THEIR PLEIOTROPIC EFFECTS IN DEPRESSION}

Since 1975, several clinical studies have been reporting that acute and chronic administration of L-type $\mathrm{Ca}^{2+}$ channel blockers (CCBs), such as nifedipine and verapamil, produces reduction in peripheral vascular resistance and arterial pressure associated with an increase in plasma noradrenaline levels and heart rate, typical signals of sympathetic hyperactivity [17]. However, the cellular and molecular mechanisms involved in this apparent sympathomimetic effect of the L-type CCBs remained unclear for decades. In addition, experimental studies using isolated tissues richly innervated by sympathetic nerves showed that neurogenic responses were completely inhibited by L-type CCBs in high concentrations $(>1 \mu \mathrm{mol} / \mathrm{L}$ ), but paradoxically potentiated in concentrations below $1 \mu \mathrm{mol} / \mathrm{L}$ [18-20]. During almost four decades, these enigmatic phenomena named by us as "calcium paradox" remained unclear. In 2013, we discovered that this paradoxical increase in sympathetic activity produced by L-type CCBs is due to $\mathrm{Ca}^{2+} / \mathrm{cAMP}$ signaling interaction [3]. Then, the pharmacological manipulation of the $\mathrm{Ca}^{2+} / \mathrm{cAMP}$ signaling interaction produced by combination of the L-type CCBs used in the antihypertensive therapy, and cAMP accumulating compounds used in the antidepressive therapy such as rolipram, could represent a potential cardiovascular risk for hypertensive patients due to increase in sympathetic hyperactivity. In contrast, this pharmacological manipulation could be a new therapeutic strategy for increasing neurotransmission in the psychiatric disorders, such as depression.

In addition, several studies have been demonstrating pleiotropic effects of CCBs. CCBs, like nifedipine, genuinely potentiate the effect of tricyclic and atypical antidepressants [21]. However, the molecular mechanisms involved in these pleiotropic effects remain under debate. In fact, apart from its classical functions, CCBs are described to have beneficiary roles on the cognitive profile of the aged population and individuals with hypertension, diabetes, Parkinson's disease, and Alzheimer's disease [22-25]. Different mechanisms have been proposed, but the exact mechanisms of antidepressant effects and cognitive improvement are still uncertain.

In contrast to adverse effects produced by combination of L-type CCBs with cAMPenhancer compounds in the cardiovascular diseases, the pharmacological implications of the $\mathrm{Ca}^{2+} / \mathrm{cAMP}$ signaling interaction produced by this drug combination could be 
used to enhance neurotransmission [3-8]. Recent studies have showed that chronic treatment with rolipram, together with typical antidepressants has been successful in the reduction of depression symptoms due to potentiation of these antidepressants effects [26]. Considering our model in which increment of [cAMP]c stimulates $\mathrm{Ca}^{2+}$ release from ER (Figure 1), it may be plausible that the therapeutic use of the PDE inhibitor rolipram $[27,28]$, in combination with low doses of verapamil to potentiate neurotransmission (Figure 1) in the areas of central nervous system involved in neurological/psychiatric disorders in which neurotransmission is reduced, including depression. This new pharmacological strategy for the treatment of psychiatric disorders could increase the therapeutic efficacy and reduce the adverse effects of the medicines currently used for treating depression. Considering that CCBs genuinely exhibit cognitive-enhancing abilities and reduce the risk of psychiatric disorders like depression [29-31] and that the mechanisms involved in these pleiotropic effects are largely unknown. Then, whether $\mathrm{Ca}^{2+} / \mathrm{cAMP}$ signaling interaction is involved in such effects deserves special attention.

In addition, considering $\left[\mathrm{Ca}^{2+}\right] \mathrm{c}$ elevation could contribute to both: negatively to neuroprotective effects and positively to exocytosis, it may be plausible the therapeutic use of the PDE inhibitors $[26,27]$ for antidepressant purposes. Then, pharmacological interference of the $\mathrm{Ca}^{2+} /$ cAMP signaling interaction produced by combination of L-type CCBs and cAMP-enhancer compounds could enhance antidepressant response and reduce clinical symptoms of psychiatric disorders. Thus, the association of currently medicines could enhance antidepressant treatments. For example: the association of typical antidepressants with CCBs or rolipram could dramatically improve typical antidepressant medicines, mainly by reducing their adverse effects and increasing their effectiveness. This new pharmacological strategy could be alternatively used for treatment of the symptoms of psychiatric disorders, including depression. Finally, special attention should be given in hypertensive patients, when treating depression by interfering on $\mathrm{Ca}^{2+} /$ cAMP signaling interaction, considering this new therapy could make hypertension worse.

\section{CONCLUSION}

The diagnosis of psychiatric disorders like depression relies critically on collaborative history of patients. In addition, emerging therapies may supplement clinical assessment in the next years. Although pharmacological therapies have been largely unsuccessful in curing depression, targeting potential risk factors aiming to decrease incidence of this psychiatric disorder is an important public health edge. Finally, novel strategies to treat depression, throughout our recent discovery entitled "calcium paradox" phenomenon due to $\mathrm{Ca}^{2+}$ /cAMP signaling interaction, could greatly contribute to enhance therapeutic strategies for increasing serotoninergic and monoaminergic neurotransmission. Thus, the association of typical antidepressants with cAMP-enhancer compounds such as rolipram could dramatically improve antidepressant therapies, mainly by reducing adverse effects and improving effectiveness of these typical antidepressants.

\section{REFERENCES}

1. Caricati-Neto A, García AG, Bergantin LB. Pharmacological implications of the $\mathrm{Ca}^{2+} / \mathrm{cAMP}$ signalling interaction: from risk for antihypertensive therapy to potential beneficial for neurological and psychiatric disorders. Pharmacol Res Perspect. 2015; 3: e00181. Ref.: https://goo.gl/BBr2kt

2. Pytka K, Podkowa K, Rapacz A, Podkowa A, Żmudzka E, et al. The role of serotonergic, adrenergic and dopaminergic receptors in antidepressant-like effect. Pharmacol Rep. 2016; 68: 263-274. Ref.: https://goo.gl/MP8VUK

3. Bergantin LB, Souza CF, Ferreira RM, Smaili SS, Jurkiewicz NH, et al. Novel model for "calcium paradox" in sympathetic transmission of smooth muscles: role of cyclic AMP pathway. Cell Calcium. 2013; 54: 202-212. Ref.: https://goo.gl/NeN9ha

4. Bergantin LB, Jurkiewicz A, García AG, Caricati-Neto A. A Calcium Paradox in the Context of Neurotransmission J Pharm Pharmacol. 2015; 3: 253-261. Ref.: https://goo.gl/hl07Cc

5. Bergantin LB, Caricati-Neto A. Challenges for the pharmacological treatment of neurological and psychiatric disorders: Implications of the $\mathrm{Ca}^{2+} / \mathrm{cAMP}$ intracellular signalling interaction. Eur $\mathrm{J}$ Pharmacol. 2016; 788, 255260. Ref.: https://goo.gl/ItZfbz 
6. Bergantin LB, Caricati-Neto A. Insight from "Calcium Paradox" due to $\mathrm{Ca}^{2+} / \mathrm{CAMP}$ Interaction: Novel Pharmacological Strategies for the Treatment of Depression. Int Arch Clin Pharmacol. 2016; 2: 2-7. Ref. https://goo.gl/QPbmtY

7. Bergantin LB, Caricati-Neto A. Novel Insights for Therapy of Parkinson's disease: Pharmacological Modulati on of the $\mathrm{Ca}^{2+} / \mathrm{cAMP}$ Signalling Interaction. Austin Neurol \& Neurosci. 2016; 1: 1-4. Ref.: https://goo.gl/XkpzlH

8. Bergantin LB, Caricati-Neto A. Recent advances in pharmacotherapy of neurological and psychiatric disorders promoted by discovery of the role of $\mathrm{Ca}^{2+} / \mathrm{CAMP}$ signaling interaction in the neurotransmission and neuroprotection. Adv Pharmac J. 2016; 1: 66-70. Ref.: https://goo.gl/9ypgJo

9. Kaster MP, Moretti M, Cunha MP, Rodrigues AL (2016). Novel approaches for the management of depressive disorders. Eur J Pharmacol. 2016; 771: 236-40. Ref.: https://goo.gl/Z5fvbG

10. Köhler $S$, Cierpinsky $K$, Kronenberg $G$, Adli $M$. The serotonergic system in the neurobiology of depression Relevance for novel antidepressants. J Psychopharmacol. 2016; 30: 13-22. Ref.: https://goo.gl/9uWF59

11. Douglas WW, Rubin RP. The role of calcium in the secretory response of the adrenal medulla to acetylcholine. $J$ Physiol. 1961; 159: 40-57. Ref.: https://goo.gl/9uWF59

12. Baker PF, Knight DE. Calcium-dependent exocytosis in bovine adrenal medullary cells with leaky plasma membranes. Nature; 1978; 276: 620-622. Ref.: https://goo.gl/ifjTU3

13. Chern YJ, Kim KT, Slakey LL, Westhead EW. Adenosine receptors activate adenylate cyclase and enhance secretion from bovine adrenal chromaffin cells in the presence of forskolin. J Neurochem. 1988; 50: 1484-1493. Ref.: https://goo.gl/Z25XIH

14. Cooper DM, Mons N, Karpen JW. Adenylyl cyclases and the interaction between calcium and cAMP signalling Nature. 1995; 374: 421-424. Ref.: https://goo.gl/w9Jklm

15. Yule DI, Betzenhauser MJ, Joseph SK. Linking structure to function: recent lessons from inositol 1,4,5-trisphosphate receptor mutagenesis. Cell Calcium. 2010; 47: 469-479. Ref.: https://goo.gl/qZbaac

16. Ahuja $\mathrm{M}$, Jha A, Maléth $\mathrm{J}$, Park $\mathrm{S}$, Muallem $\mathrm{S}$. cAMP and $\mathrm{Ca}^{2+}$ signaling in secretory epithelia: crosstalk and synergism. Cell Calcium. 2014; 55: 385-93. Ref.: https://goo.gl/v5sEi7

17. Grossman E, Messerli FH. Effect of calcium antagonists on sympathetic activity. Eur Heart J. 1998; 19: 27-31. Ref.: https://goo.gl/3VaR2B

18. Kreye VA, Luth JB. Proceedings: verapamil-induced phasic contractions of the isolated rat vas deferens. Naunyn Schmiedebergs Arch Pharmacol. 1975; 287: R43. Ref.: https://goo.gl/34bQaA

19. French AM, Scott NC. A comparison of the effects of nifedipine and verapamil on rat vas deferens. Br J Pharmacol. 1981; 73: 321-323. Ref.: https://goo.gl/gfli14

20. Moritoki H, Iwamoto $T$, Kanaya J, Maeshiba $Y$, Ishida $Y$, et al. Verapamil enhances the non-adrenergic twitch response of rat vas deferens. Eur J Pharmacol. 1987; 140: 75-83. Ref.: https://goo.gl/0yeqf1

21. Prakhie IV, Oxenkrug GF. The effect of nifedipine, $\mathrm{Ca}(2+)$ antagonist, on activity of MAO inhibitors, $\mathrm{N}$-acetylserotonin and melatonin in the mouse tail suspension test. Int $\mathrm{J}$ Neuropsychopharmacol. 1998; 1: 35-40. Ref. https://goo.gl/qDZmkH

22. Ogihara $T$, Nakagawa $M$, Ishikawa $H$, Mikami $H$, Takeda $K$, et al. Effect of manidipine, a novel calcium channel blocker, on quality of life in hypertensive patients. Blood Press Suppl. 1992; 3: 135-139. Ref. https://goo.gl/OCWfvh

23. Veng LM, Mesches MH, Browning MD. Age-related working memory impairment is correlated with increases in the L-type calcium channel protein a1D (Cav1.3) in area CA1 of the hippocampus and both are ameliorated by chronic nimodipine treatment. Brain Res Mol Brain Res. 2003; 110: 193-202. Ref.: https://goo.gl/J1/gy5

24. Chan CS, Guzman JN, Ilijic E, Mercer JN, Rick C, et al. 'Rejuvenation' protects neurons in mouse models of Parkinson's disease. Nature. 2007; 447: 1081-1086. Ref.: https://goo.gl/d2EjVz

25. Tsukuda K, Mogi M, Li JM, Iwanami J, Min LJ, et al. Diabetes-associated cognitive impairment is improved by a calcium channel blocker, nifedipine. Hypertension. 2008; 51: 528-533. Ref.: https://goo.gl/zgud8g

26. Sommer N, Loschmann PA, Northoff GH, Weller M, Steinbrecher A, et al. The antidepressant rolipram suppresses cytokine production and prevents autoimmune encephalomyelitis. Nat Med. 1995; 1: 244-248. Ref. https://goo.gl/eXv7C8

27. Li YF, Cheng YF, Huang Y, Conti M, et al. Phosphodiesterase-4D knock-out and RNA interference-mediated knockdown enhance memory and increase hippocampal neurogenesis via increased cAMP signaling. J Neurosci. 2011 31: 172-183. Ref.: https://goo.gl/fCsYtf

28. Xiao L, O'Callaghan JP, O'Donnell JM. Effects of repeated treatment with phosphodiesterase-4 inhibitors on cAMP signaling, hippocampal cell proliferation, and behavior in the forced-swim test. J Pharmacol Exp Ther. 2011; 338: 641-647. Ref.: https://goo.gl/myAhrx

29. De Vry J, Fritze J, Post R. The management of coexisting depression in patients with dementia: potential of calcium channel antagonists. Clinical Neuropharmacology. 1997; 20: 22-35. Ref.: https://goo.gl/OlvzJr

30. Vetulani J. The action of antidepressant drugs administered during calcium channel blockade. Pol J Pharmacol. 1993; 45: 179-84. Ref.: https://goo.gl//fGE3E

31. Taragano FE, Bagnatti P, Allegri RF. A double-blind, randomized clinical trial to assess the augmentation with nimodipine of antidepressant therapy in the treatment of "vascular depression". Int Psychogeriatr. 2005; 17: 487498. Ref.: https://goo.gl/19kry3 